\title{
Communication Strategies and Attitude: Interactive Concepts in Adult Literacy Teaching
}

\author{
E. Oluwakemi Augustus Ph. D \\ Federal College of Agriculture, Ibadan, Oyo State, Nigeria.
}

\begin{abstract}
This paper examined two important concepts: communication or instructional strategies and attitude of adult learners in a successful adult literacy teaching/learning situation. A 3x2x2 quasi-experimental, pre-test, post-test control group design was employed. The subjects for the study were three hundred and four (304) intermediate class adult learners purposively selected from sixteen (16) adult literacy centres in Ibadan, Oyo State, Nigeria. Three hypotheses were generated and tested at 0.05 Alpha level. The instruments used for the study were (a) A recorded cassette containing teachings on the selected concepts. (b) Learners' Achievement Test (LAT) in civic literacy education (c) Learners' Attitude towards Civic Literacy Education Questionnaire (LATCLEQ).

The study for this paper lasted ten (10) weeks. The data obtained were analysed using Analysis of Covariance (ANCOVA), Multiple Classification Analysis (MCA) and Scheffe post-hoc test. The results show that: there was significant main effect of treatment on learners' achievement in civic literacy education $\left(F_{(2,303)}\right.$ $=19.92 ; p<0.05)$. From this study, learners' taught with drama communication strategy made a significant gain in knowledge with the highest mean score of 81.304 followed by those taught with audio-based communication package with a mean score of 76.9. The conventional (chalkboard) method group contributed least with a mean score of 63.79 .

Interestingly, the study revealed a significant main effect of treatment on attitude towards civic literacy education $\left(F_{(2,303)}=6.282 ; p<0.05\right)$. However, there was no significant main effect of gender on learners' achievement in civic literacy education $\left(F_{(1,303)}=2.167 ; p>0.05\right)$ as well as learners' attitude towards civic literacy education $\left(F_{(1,303)}=2.138 ; p>0.05\right)$. The findings also reveal that there was a significant main effect of learners' socio-economic status on achievement in civic literacy education $\left(F_{(1,303)}=5.225 ; p<0.05\right)$ and learners' attitude towards civic literacy education $\left(F_{(1,303)}=8.970 ; p<0.05\right)$. The findings further show that there was a significant interaction effect of treatment and learners' socio-economic status on achievement in civic literacy education $\left(F_{(2,303)}=6.461 ; p<0.05\right)$, as well as attitude towards civic literacy education $\left(F_{(2,303)}=\right.$ 8.972; $p>0.05)$. Based on these findings, it was recommended that effective, participatory and interesting communication strategies like drama and audio-instruction should be used in adult literacy teaching/learning situation to facilitate or enhance positive attitude towards achieving effective learning which is the goal of literacy programme.
\end{abstract}

Key words: Communication strategies, Literacy teaching and Attitude

\section{Introduction}

Attitude is generally viewed differently by two schools of thought: the mentalist and the behaviourist. The mentalist sees attitude as mental and neural state of readiness that is, attitude cannot be directly observed but must be inferred by the subject's introspection. Thus, Baker (1992) cited in Adelore (2000) defines attitudes as a hypothetical construct used to explain the direction and persistence of human behaviour by references to relatively stable and enduring dispositions in people. Attitudes cannot be directly observed. A person's thoughts processing system and feelings are hidden. Therefore, attitudes are latent, inferred from behaviour. A common expression of attitude is an opinion. However, Fasold (1984) cited in Adelore (2000) expresses the behaviourist view and claims that attitude or disposition is simply overt, an observable response to social situations. It is regarded as a dependent variable. In essence, no need to observe, tabulate and analyse overt behaviour. Considering the foregoing, Adelore (2000) arrives at a working definition and defined attitude as value, feeling, outlook and belief about a concept. It is on these features that we value and judge that particular concept. Attitude affects behaviour, hence it affects learning. Adult literacy teaching therefore can be exciting and productive if adult learners have a positive attitude towards adult literacy teaching and it can be frustrating if their attitude is negative.

It is also important to note that adult education according to Bown and Tomori (1980) is the education of persons who are physiologically matured and are socially and economically responsible. Adult learners are different from children and other beneficiaries of regular school programmes. Adult learners have peculiar psychological and sociological characteristics which must be duely considered in planning adult literacy contents and communication or instructional strategies to achieve positive learning attitude from the adult 
learners. Adults do not learn unless they have the need to learn. Hence, the choice of civic literacy education for this study to develop a spirit of national consciousness and patriotism through the study of their physical and social environment at this period of national threat on democracy in our nation. Another peculiar characteristic of the adults is that adult learners object to authoritarian method of teaching and reluctant to recognize their own lack of knowledge or skill. Adults only learn best when they have some control over the learning environment. Hence, participatory communication like drama was employed for this study.

Castle (1978) defines communication strategy or instructional method as the practical application of good teaching principle based on the nature of the subject and the learning needs of the learners. This definition basically addresses the sociological and psychological make-up of the learners which is a vital factor to be considered to elicit positive attitude in adult literacy teaching and learning situation. Aderinoye (1997) also stresses that if the adult reaches his immediate goal and the process is tolerable, he will tend to develop longertime goals and continue with adult education. The implication of this is that eliciting a positive attitude from adult learner and his continuity in an adult literacy class and achieving the desired goal which is learning depend on the appropriateness of the communication strategies or instructional methods. Selection of communication strategies in adult literacy teaching/learning process therefore calls for prudence and sound judgment on the part of instructors and adult educator as a whole in achieving the desired objectives of learning. The experimental study therefore examined interaction of communication or instructional strategies and attitude of adult learners in a successful adult literacy education learning context.

\section{Research Hypotheses and Methodology}

The following null hypotheses were tested:

$\mathrm{HO}_{1}$ : There is no significant main effect of treatment on adult learners' (a) achievement in civic literacy education (b) attitude towards civic literacy education.

$\mathrm{HO}_{2}$ : There is no significant main effect of gender on adult learners' (a) achievement in civic literacy education (b) attitude towards civic literacy education.

$\mathrm{HO}_{3}$ : There is no significant main effect of learners' socio-economic status on adult learners' (a) achievement in civic literacy education (b) attitude towards civic literacy education.

\section{Results and Discussions}

Hypothesis 1 states that there is no significant main effect of treatment on adult learners' (a) achievement in civic literacy education (b) attitude towards civic literacy education.

Table 1: Analysis of covariance (ANCOVA) of the post-test achievement scores of learners (according to treatment, gender, and socio-economic status) in civic literacy education

\begin{tabular}{|c|c|c|c|c|c|}
\hline Source of Variation & Sum of Squares & DF & Mean Square & $\mathbf{F}$ & Significance \\
\hline Covariates & 10338.388 & 1 & 10338.388 & 22.794 & $.000 *$ \\
\hline $\mathrm{V}_{2}$ & 10338.388 & 1 & 10338.388 & 22.794 & $.000 *$ \\
\hline Main Effects & 21528.031 & 4 & 5382.008 & 11.866 & $.000^{*}$ \\
\hline Vi (Treatment) & 18073.710 & 2 & 9036.855 & 19.925 & $.000^{*}$ \\
\hline $\mathrm{V}_{4}(\mathrm{SES})$ & 2369.979 & 1 & 2369.979 & 5.225 & $.023 *$ \\
\hline Gender & 982.723 & 1 & 982.723 & 2.167 & .142 \\
\hline 2-way Interactions & 7620.015 & 5 & 1524.003 & 3.360 & .006 \\
\hline $\begin{array}{lll}\mathrm{V}_{1} & \mathrm{x} & \mathrm{V}_{4} \\
\end{array}$ & 5861.111 & 2 & 2930.555 & 6.461 & $.002 *$ \\
\hline $\mathrm{V}_{1} \mathrm{x}$ Gender & 1986.567 & 2 & 993.284 & 2.190 & .114 \\
\hline $\mathrm{V}_{4} \times \mathrm{x}$ Gender & 124.379 & 1 & 124.379 & .274 & .601 \\
\hline 3-way Interactions & 944.622 & 2 & 472.311 & 1.041 & .354 \\
\hline $\mathrm{V}_{1} \times \mathrm{V}_{4} \times$ Gender & 944.622 & 2 & 472.311 & 1.041 & .354 \\
\hline Explained & 40431.057 & 12 & 3369.225 & 7.429 & .000 \\
\hline Residual & 131982.890 & 291 & 453.549 & & \\
\hline Total & 172413.947 & 303 & 569.023 & & \\
\hline
\end{tabular}

$*$ Significant at $\mathrm{P}<0.05$

Table 2: Analysis of Covariance (ANCOVA) of the Post-attitude Scores of Learners to Civic literacy education

\begin{tabular}{|l|l|l|l|l|l|}
\hline Source of Variation & Sum of Squares & DF & Mean Square & F & Significance \\
\hline Covariates & 5228.825 & 1 & 5228.825 & 65.204 & $.000^{*}$ \\
\hline PRE SSQ & 5228.825 & 1 & 5228.825 & 65.204 & $.000^{*}$ \\
\hline Main Effects & 1701.302 & 4 & 425.325 & 5.304 & $.000^{*}$ \\
\hline $\mathrm{V}_{1}$ & 1007.492 & 2 & 503.746 & 6.282 & $.002^{*}$ \\
\hline $\mathrm{V}_{4}$ & 704.894 & 1 & 704.894 & 8.790 & $.003^{*}$ \\
\hline Gender & 171.490 & 1 & 171.490 & 2.138 & .145 \\
\hline 2-way Interactions & 1846.292 & 5 & 369.258 & 4.605 & .000 \\
\hline $\mathrm{V}_{1} \mathrm{X} \mathrm{V}_{4}$ & 1439.016 & 2 & 719.508 & 8.972 & $.000^{*}$ \\
\hline
\end{tabular}


Communication Strategies And Attitude: Interactive Concepts In Adult Literacy Teaching

\begin{tabular}{|l|l|l|l|l|l|}
\hline $\mathrm{V}_{1} \times$ Gender & 214.409 & 2 & 107.205 & 1.337 & .264 \\
\hline $\mathrm{V}_{4} \mathrm{X}$ Gender & 107.563 & 1 & 107.563 & 1.341 & .248 \\
\hline 3-way Interactions & 825.763 & 2 & 412.881 & 5.149 & .006 \\
\hline $\mathrm{V}_{1} \times \mathrm{V}_{4} \times$ Gender & 825.763 & 2 & 412.881 & 5.149 & $.006^{*}$ \\
\hline Explained & 9602.181 & 12 & 800.182 & 9.978 & .000 \\
\hline Residual & 22774.633 & 291 & 78.263 & & \\
\hline Total & 32376.815 & 106.854 & & \\
\hline
\end{tabular}

* Significant at $\mathrm{P}<0.05$

Tables 1 and 2 represent the ANCOVA for the three dependent variables. The results show a significant main effect of treatment on learners' achievement in civic literacy education $\left(\mathrm{F}_{(2,303)}=19.93 ; \mathrm{p}<0.05\right)$. And learners' attitude to civic literacy education $\left(\mathrm{F}_{(2,303)}=6.282 ; \mathrm{P}<0.05\right)$. Therefore, hypothesis $1 \mathrm{a}$ and $\mathrm{b}$ were rejected.

Table 3: Multiple classification analysis of the post-test achievement in civic literacy education Grand Mean $=74.987$

\begin{tabular}{|c|c|c|c|c|c|}
\hline Variable + Category & $\mathbf{N}$ & $\begin{array}{l}\text { Unadjusted } \\
\text { Deviation }\end{array}$ & Eta & $\begin{array}{l}\text { Adjusted for } \\
\text { Independent + Covariates } \\
\text { Deviation }\end{array}$ & Beta \\
\hline $\begin{array}{l}\text { V1 } \\
\text { 1. Drama Method } 2 . \\
\text { Audio-based Instruction } \\
\text { 3. Control }\end{array}$ & $\begin{array}{l}125 \\
92 \\
87\end{array}$ & $\begin{array}{l}6.322 .00 \\
-11.19\end{array}$ & & $\begin{array}{l}6.123 .07 \\
-12.04\end{array}$ & \\
\hline & & & .31 & & 0.32 \\
\hline $\begin{array}{l}\text { V4 1. High } \\
\text { 2. Low }\end{array}$ & $\begin{array}{l}101 \\
196\end{array}$ & $3.57-1.97$ & & $3.85-2.12$ & \\
\hline & & & .11 & & .12 \\
\hline $\begin{aligned} & \text { Gender 1. } \text { Male } \\
& \text { 2. } \text { Female } \\
&\end{aligned}$ & $\begin{array}{l}104 \\
200\end{array}$ & $2.81-1.46$ & & $2.54-1.32$ & \\
\hline & & & .09 & & .08 \\
\hline Multiple R Square & & & & & .185 \\
\hline Multiple R & & & & & .430 \\
\hline
\end{tabular}

The Multiple Classification Analysis shown in Table 3 provides an additional insight to the result with regard to post-test adjusted means of each of the groups as defined by the level of dependent variables. Experimental group 1 - Drama Method was found to have recorded the highest mean score of 81.107, followed by the audio-based instruction (experimental group 2) with a mean score of 78.057. The conventional method (control group) contributed least with a mean score of 62.94. Moreover, learners of high socio-economic status with a mean score of 78.837 performed better than those of low socio-economic status with a mean score of 72.867.

Table 4: Multiple classification analysis of the post-attitude scores to civic literacy education Grand Mean $=53.185$

\begin{tabular}{|c|c|c|c|c|c|}
\hline Variable + Category & $\mathbf{N}$ & $\begin{array}{l}\text { Unadjusted } \\
\text { Deviation }\end{array}$ & Eta & $\begin{array}{l}\text { Adjusted for } \\
\text { Independent + } \\
\text { Covariates } \\
\text { Deviation }\end{array}$ & Beta \\
\hline $\begin{array}{ll}V_{1} & \\
\text { 1. } & \text { Drama Method } \\
\text { 2. } & \text { Audio-based Instruction } \\
\text { 3. } & \text { Control }\end{array}$ & $\begin{array}{l}125 \\
92 \\
87\end{array}$ & $\begin{array}{r}1.18 \\
1.64 \\
-3.60 \\
\end{array}$ & & $\begin{array}{l}-.03 \\
2.34 \\
-2.53\end{array}$ & \\
\hline & & & .21 & & .18 \\
\hline $\begin{array}{l}\mathrm{V}_{4} \\
\text { 1. High } \\
\text { 2. Low }\end{array}$ & $\begin{array}{l}108 \\
196\end{array}$ & $\begin{array}{l}-.65 \\
.34\end{array}$ & & $\begin{array}{l}2.41 \\
-1.24\end{array}$ & \\
\hline & & & .04 & & .17 \\
\hline $\begin{array}{ll}\text { Gender } \\
\text { 1. } \text { Male } \\
\text { 2. } \text { Female }\end{array}$ & $\begin{array}{c}104 \\
200\end{array}$ & $\begin{array}{c}-2.03 \\
1.03\end{array}$ & & $\begin{array}{l}-1.10 \\
.56\end{array}$ & \\
\hline & & & .14 & & .08 \\
\hline Multiple R Square & & & & & .214 \\
\hline Multiple R & & & & & .463 \\
\hline
\end{tabular}

The Multiple Classification Analysis (MCA) as shown in Table 4 describes the attitude scores of learners in all the groups. Learners exposed to audio-based instruction had best attitude towards civic literacy education with a mean score of 55.535 followed by those exposed to drama method of instruction with a mean score of 53.155. Those learners exposed to the conventional method had the least mean score of 50.655. 
Table 6: Post-Hoc analysis of learners' attitude to civic literacy education

\begin{tabular}{|l|l|l|l|l|}
\hline Mean & Group & Group 3 & Group 2 & Group 1 \\
\hline 49.5854 & Group 3 & & & \\
\hline 52.8551 & Group 2 & $*$ & & \\
\hline 54.8222 & Group 1 & $*$ & & \\
\hline
\end{tabular}

* Significant at $\mathrm{P}<0.05$

Table 6 further shows that there exists a significant difference between the control group and the two experimental groups - drama method and audio-based instructional package.

In other words, table 6 shows that there is a significant difference between group 1 drama method and 3 (conventional method). The means for experimental groups 1 and 2 are significantly higher $(54.8222,52.8551)$ than the mean of the control group (49.5854) for learners' attitude towards civic literacy education.

These facts show that the method of instruction has a significant main effect on the variations of the adult learners' attitude scores towards civic literacy education. In effect, audio-based instruction followed by drama method play significant role in enhancing adult learners' attitude towards civic literacy education. This finding is in accordance with Oakely (1985) who affirms that drama like puppet shows, theatrical plays and role plays are excellent media for sharing educational stories with large group. They are entertaining and unlike any other media, have the potential of dragging the audience (learners) into the message by means of the true-to life character of the performers and the immediacy of the teaching. Okafor (1998) also confirms the finding of this study. In his study, there was a significant main effect of cooperative learning and conceptual change pedagogical strategies on achievement and attitude towards chemistry respectively.

\section{The main effect on gender on adult learning cognitive and affective outcomes}

Hypothesis 2 states that there is no significant main effect of gender on (a) achievement in civic literacy education (b) learners attitude to civic literacy education.

The results on Table 1 and 2 reveal that there is no significant main effect of gender on learners' achievement in civic literacy education $\left(\mathrm{F}_{(1,303)}=3.167 ; \mathrm{p}>0.05\right)$ and learners attitude to civic literacy education $\left(F_{(1,303)}=2.138 ; p>0.05\right)$. Therefore, hypotheses $2 \mathrm{a}$ and $2 \mathrm{~b}$ were not rejected.

To find the difference between the male and female respondents, Multiple Classification Analysis (MCA) presented in Tables 3 and 4 reveal that the means for male were 77.527 and 52.085 for achievement in civic literacy education and attitude to civic literacy education while their female counterparts had means of 73.667 and 53.745 in achievements in civic literacy education and attitude to civic literacy education respectively.

The mean difference of adult male -52.085 and female learners -53.745 with respect to attitude in civic literacy education shows that female learners tend to have positive attitude to civic literacy education than male learners. The reason might be that the contents of civic literacy education treated were of interest to the female learners than the male learners.

\section{The main effect of socio-economic status on learners' cognitive and affective outcomes.}

Hypothesis 3 states that there is no significant main effect of learners' socio-economic status on learners (a) achievement in civic literacy education (b) attitude to civic literacy education.

The research results on Tables 1 and 2 show that there was significant main effect of learners' socioeconomic status on learners' achievement in civic literacy education $\left(\mathrm{F}_{(1,303)}=5.225 ; \mathrm{p}<0.05\right)$ and learners' attitude to civic literacy education $\left(\mathrm{F}_{(1,303)}=8.790 ; \mathrm{p}<0.05\right)$. Therefore, hypotheses $3 \mathrm{a}$ and $3 \mathrm{~b}$ were rejected.

Tables 3 and 4 show the Multiple Classification Analysis for learners' achievement in civic literacy education and learners attitude to civic literacy education. The mean score of learners of high socio-economic status 78.837 and learners of low socio-economic status 72.867 with respect to achievement in civic literacy education reveal that learners of high socio-economic status performed better than those of low socio-economic status. Also, learners of high socio-economic status with a mean score of 55.595 had positive attitude to civic literacy education more than those of low socio-economic status with a mean score of 52.945 .

These results contradict the research finding of Okediran (1988) that learners' socio-economic status has no effect on learners' achievement in Yoruba Reading.

\section{Conclusion and Recommendations}

This study shows through verifiable evidence that appropriate communication or instructional strategies like drama and audio-based instruction are effective in adult teaching/learning situation. They also contribute significantly to the learners' positive attitude to the curricular subject that is, civic literacy education. These results underscore the need for adult education planners, curriculum planners, policy makers and facilitators to always consider characteristics of the adult learners before the choice of any method of teaching and adopt participated and interesting communication instructional strategies like drama and audio-tape instruction to enhance full participation of adults learners in adult teaching/learning exercise. This will engender 
positive and favourable attitude of adult learners toward adults teaching/learning programme and ultimately achieve the whole essence of mass literacy education programme.

Socio-economic status of adult learners also made significant contribution to the prediction of adult learning attitude towards civic literacy education. On this premise, learners of both high and low socioeconomic status should be equally motivated to learn. Adult literacy planners should ensure provision of literacy centres at strategic areas for easy accessibility for all categories of learners.

All international, governmental and non-governmental agencies should motivate all categories of learners by assisting in funding literacy programmes. Also, incentives such as stationery, primers and others should be supplied free of charge or at minimum costs to learners.

In this study, gender as a variable did not show any significant relationship to learners' attitude towards civic literacy education. It is therefore, important for the government, curriculum planners and adult education practitioners to note that both male and female learners can be effectively taught using the same communication or instructional strategies like drama and audio-taped instruction.

It is a general belief that adult learners are experienced, have their own will, know what they want and at times critical of their primer. Adult education curriculum planners and adult primer writers should make the curriculum and the primer more relevant and situational woven around the learners need and interests.

In any adult literacy teaching/learning situation therefore, the study on attitudes helps in adult literacy policy formulation and it behooves adult literacy education facilitators, policy makers and curriculum planners to ensure that adult literacy education achieve its goals and objectives.

\section{References}

[1]. Adelore, O.O. (2000). Language learning attitudes among selected ethnic groups in Adult literacy programmes in Nigeria. Unpublished Ph.D Thesis, University of Ibadan.

[2]. Aderinoye, R.A. (1997). Literacy education in Nigeria. Ibadan: Ibadan University Press.

[3]. Augustus, E.O., Okediran, A. and Adeniran, M. (2003). Some correlates of language learning attitude among college students. Journal of English Language Teaching Today (ELTT). Vol. 2, No. 1, pp. 7-11.

[4]. Fasold, R. (1984). The sociolinguistic of society. Oxford: Basil Blackwell.

[5]. Okafor, N.P. (1998). Eliminating communication barriers in adult teaching/learning process. A paper presented at the 20th National Conference of Nigeria Association for Educational Media and Technology (NAEMT) at University of Lagos between 2nd - 5th November.

[6]. Okediran, A. (1988). An experimental study of different approaches to teaching reading to adult learners. An unpublished Ph.D. Thesis, University of Ibadan, Ibadan. 